\title{
Relação entre consciência fonológica e compreensão leitora em crianças: revisão sistemática de pesquisas brasileiras
}

\author{
The relationship between phonological awareness and reading comprehension in children: \\ systematic review of Brazilian researches
}

La relación entre conciencia fonológica y comprensión lectora en niños: revisión sistemática de investigaciones brasileñas

Jordana Taís Konrad ${ }^{1}$

Aline Lorandi 1

1 Universidade do Vale do Rio dos Sinos, São Leopoldo, RS, Brasil.

$\diamond$

\section{RESUMO}

Esta revisão sistemática objetiva apresentar estudos brasileiros que investigam o papel da consciência fonológica como meio facilitador da compreensão leitora de crianças em processo de aquisição da língua escrita. A busca foi realizada em diferentes bases eletrônicas de dados, e os descritores utilizados foram: "consciência fonológica", "leitura", "compreensão leitora" e "crianças". Com base nos critérios de inclusão, o levantamento identificou seis trabalhos. Os resultados evidenciaram que a consciência fonológica contribui tanto para a melhora da leitura e da compreensão quanto para o aumento da velocidade da leitura e da compreensão. Esses resultados lançam luz sobre a importância de investigações, na área da Linguística Aplicada, que se ocupem da relação entre consciência linguística e leitura durante a aquisição da linguagem.

Palavras-chave: Consciência fonológica. Leitura. Compreensão leitora. Alfabetização.

\section{ABSTRACT}

This systematic review aims to present Brazilian studies that investigate the role of phonological awareness as a way of improving reading comprehension in children during literacy. The search was made in different electronic databases, and the keywords used were: "phonological awareness", "reading", "reading comprehension", and "children". Based on the inclusion criteria, the search resulted in six papers. The results showed that phonological awareness, in fact, improves not only reading per se, but also the speed of reading and reading comprehension. These results shed some light on the importance of investigations in the area of Applied Linguistics, in order to provide different ways of looking to the relationship between linguistic awareness and reading in first language acquisition.

Keywords: Phonological awareness. Reading. Reading comprehension. Literacy.

\section{RESUMEN}

Esta revisión sistemática objetiva presentar estudios brasileños que investigan el rol de la conciencia fonológica como medio facilitador a la comprensión lectora de niños en proceso de adquisición de lengua escrita. La búsqueda ha sido realizada en diferentes bases electrónicas de datos, y los descriptores utilizados han sido: "conciencia fonológica", "lectura", "comprensión lectora" y "niños". Con base en los criterios de inclusión, la recopilación ha identificado seis trabajos. Los resultados han evidenciado que la conciencia fonológica contribuye tanto para mejorar la lectura y la comprensión como para el aumento de la velocidad de la lectura y de la comprensión. Esos resultados lanzan luz sobre la importancia de investigaciones, en el área de la Linguística Aplicada, que se ocupen de la relación entre conciencia linguística y lectura durante la adquisición del lenguaje.

Palabras clave: Conciencia fonológica. Lectura. Comprensión de lectura. Alfabetización 


\section{Introdução}

O papel da consciência fonológica sobre a aprendizagem da leitura é amplamente referenciado na literatura (BRADLEY; BRYANT, 1983, GOSWAMI; BRYANT, 1990; SCHERER, 2007; CAPOVILLA, GÜTSCHOW, CAPOVILLA, 2004; BARRERA; MALUF, 2003), assim como a importância da realização de atividades de consciência fonológica como forma de estimulação para o processo de alfabetização (SCHERER, 2007; WOLF, 2015; BARRERA; MALUF, 2003). Nesta revisão, optou-se em delimitar a amostra a aprendizes sem distúrbios de aprendizagem.

Apesar de vários estudos já evidenciarem o valor da instrução explícita da consciência fonológica no desenvolvimento de habilidades para a alfabetização, no sentido da decodificação da escrita, como foi possível constatar na busca, ainda são poucas as atividades metalinguísticas promovidas no âmbito escolar brasileiro. O objetivo principal deste artigo, contudo, é lançar um olhar para o possível papel da consciência fonológica nas habilidades de leitura, ao propor uma revisão da literatura que responda à questão sobre se há impacto da estimulação da consciência fonológica sobre as habilidades de leitura, de modo especial em relação à compreensão.

\section{Consciência linguística/ consciência fonológica}

A capacidade de ir além da percepção auditiva e alcançar a habilidade metalinguística é o que se denomina uma atividade de reflexão sobre os aspectos fonológicos da língua. $\mathrm{Na}$ literatura, encontramos várias definições para o termo "consciência fonológica" (doravante CF). Para este estudo, porém, optou-se pela ótica apresentada por Lorandi (2011) e Lorandi e Marques (2016), pois a CF é definida de maneira a extrapolar a tradicional visão da consciência em dois níveis - implícito e explícito captando sutilezas desenvolvimentais importantes, por meio da postulação de quatro níveis - um implícito (procedimental) e três explícitos, que se diferem entre si em termos de explicitude, acesso consciente ao conhecimento e capacidade de verbalização. O conceito de CF proposto por Lorandi (2011) e Lorandi e Marques 2016) ancora-se no modelo de Redescrição Representacional, de Karmiloff-Smith (1986, 1992, 1994).

A consciência fonológica [pode] ser entendida como o alcance de determinados níveis de representação mental, em que gradualmente o conhecimento fonológico em nível de sílaba e em nível de fonema é redescrito, tornando-se gradualmente mais flexível e manipulável, tomando sílaba, fonema e elementos suprassegmentais como objetos de análise, em oposição ao seu uso procedimental para produção e compreensão de palavras e sentenças (LORANDI; MARQUES, 2016, p.3).

Para Alves (2012, p.31), “além dessa capacidade de reflexão sobre os sons da língua, é fundamental que o indivíduo manipule as unidades sonoras das quais se mostra consciente, apagando, adicionando, ou substituindo sons". Contudo, ele reforça que o conhecimento formal e a habilidade de manipulação dessas unidades sonoras implicam diferentes níveis de consciência fonológica, que emergem naturalmente em fases distintas do desenvolvimento linguístico.

\begin{abstract}
Uma vez que se trata de capacidades de operar sobre unidades bastante distintas, vê-se que os diferentes níveis de consciência fonológica se desenvolvem em um continuum de complexidade, indo desde uma sensibilidade às rimas de palavras, passando pela capacidade de manipulação de sílabas e de unidades intrassilábicas (menores que uma sílaba) e indo até a menor unidade de som capaz de mudar significado, o fonema (ALVES, 2012, p. 32).
\end{abstract}

Portanto, essa consciência pode ser instigada antes mesmo de a criança ingressar na escola, pois "passa por etapas na aquisição da linguagem, aprimora seu inventário fonológico e desenvolve, concomitantemente, os níveis mais elementares em consciência fonológica" (BLANCO-DUTRA; SCHERER; BRISOLARA, 2012, p. 75).

\section{Leitura e compreensão leitora}

O papel facilitador das habilidades metalinguísticas (conhecimentos fonológicos, morfológicos e sintáticos) e, em especial, o estudo das relações entre o processamento fonológico e as habilidades de leitura em sistemas alfabéticos vem despertando a atenção de muitos pesquisadores preocupados com a aquisição da linguagem.

A existência da correlação entre o nível de consciência fonológica e o desempenho em atividades de leitura e escrita tem sido demonstrada por uma grande quantidade de pesquisas (Morais, Cary, Alegria \& Bertelson, 1979; Morais et al., 1986; Read, Zhang, Nie\&Ding, 1986; Brandley \& Bryant, 1983; Manrique \& Signorini, 1988; Martins, 1991; Morais, 1994; Maluf \& Barrera, 1997). Alguns autores (Morais et al., 1979; Read et al., 1986) acreditam ser a instrução formal no sistema alfabético o fator ou causa primordial para o desenvolvimento da consciência fonológica, há também aqueles (Bradley \& Bryant, 1983) que defendem o ponto de vista que a consciência fonológica constitui um pré-requisito para a aquisição da linguagem escrita (BARRERA, 2003, p. 72). 
Assim sendo, não há dúvidas de que a consciência fonológica é a chave para aprender a escrever línguas com ortografia alfabética (CARDOSO-MARTINS, 1995), pelo menos quando se trata de desenvolvimento típico da escrita.

A competência leitora, por sua vez, é desenvolvida de forma progressiva e, por vezes, lenta, visto que é uma atividade bastante complexa, pois "envolve a coordenação rápida de processos visuais, fonológicos, semânticos e linguísticos" (PLAUT, 2013, p.42). Dessa maneira, a leitura envolve o processamento de informações: transformar escrita em fala e escrita em significado (COLTHEART, 2013, p.24).

Um pré-requisito para a compreensão que condiciona toda atividade de leitura é o reconhecimento das palavras, que deveria ocorrer de forma automática, sem que o leitor percebesse que está efetuando um trabalho intelectual (GOMBERT, 2003). Para o autor, "é preciso que todo o esforço consciente seja mobilizado para o objetivo pelo qual o leitor lê e não pela utilização da ferramenta leitura" (2003, p. 29). Porém, ele explica que a leitura de palavras desconhecidas, nunca antes vistas pelo sujeito, requer a capacidade de reconstruir a palavra oral conhecida a partir da configuração visual, sendo necessário, nesse caso, o domínio da correspondência grafo-fonêmica. Por isso, a atividade de leitura supõe o domínio de certos aspectos fonológicos.

Em 1985, a psicóloga Uta Frith propôs o modelo dos três estágios da leitura, a saber: a logográfica ou pictórica, a fonológica e a ortográfica. A primeira etapa surge por volta dos 5 a 6 anos e é a fase em que a criança, por meio do seu sistema visual, reconhece as palavras da mesma forma como objetos e rostos que a rodeiam. Na segunda etapa, a fonológica, a criança associa cada cadeia de letras a sua pronúncia, por um procedimento sistemático de conversão dos grafemas aos fonemas, que costuma iniciar com o ingresso na escola aos 6 ou 7 anos. E, por fim, na etapa ortográfica, a criança apresenta um vasto repertório de unidades visuais de tamanho variável (DEHAENE, 2012, p. 217).

São muitas as variáveis que podem influenciar o processo de leitura e de compreensão leitora de uma criança, como por exemplo: "fatores externos, como o nível sócio-econômico-cultural; os aspectos pedagógicos, metodológicos, ambientais e fatores internos como o nível maturacional, intelectual, aspectos emocionais, grau de sensibilidade linguística (metalinguística), entre outros" (CIELO; POERSCH, 1998, p. 102). Nesse sentido, avaliar sucessos ou insucessos no desenvolvimento dessa habilidade pode ser um desafio.

Quais são e como funcionam os diferentes componentes e mecanismos envolvidos na leitura são aspectos que necessitam ser incessantemente pesquisados e aprofundados, pois a compreensão do processo da leitura e da natureza desse sistema é a chave para a melhora da prática educativa. Não se pode exigir da criança determinada habilidade sem antes ter-lhe dado subsídios para que possa obter sucesso na aprendizagem da leitura. A consciência fonológica, grande aliada da decodificação da escrita, pode favorecer habilidades de leitura. Portanto, cabe ao professor pensar em atividades de consciência fonológica que ajudarão o aluno a se tornar em um bom leitor que compreende aquilo que lê.

\section{Metodologia}

Este estudo teve como metodologia a busca de artigos científicos que pudessem responder à seguinte pergunta norteadora: qual a relação entre consciência fonológica e compreensão leitora de crianças em processo de aprendizagem monolíngue da língua escrita? Para a busca do material, foram estabelecidas as seguintes palavraschave: "consciência fonológica", "leitura", "compreensão leitora" e "língua materna". Visou-se a encontrar estudos feitos no Brasil, por isso, o idioma se restringiu ao português. De 1 a 20 de dezembro de 2016 foi realizada a busca nas bases de referências bibliográficas, sendo usados os portais e bases de dados eletrônicos: portal de periódicos da Capes, do Scielo e Google Acadêmico.

O critério de inclusão foi a referência dos termos "consciência fonológica e leitura/compreensão leitora" no título dos artigos. Em seguida, a partir da leitura dos resumos, identificaram-se os participantes de pesquisa, que deveriam ser crianças brasileiras em processo de alfabetização, de $1^{\circ}$ ano a $5^{\circ}$ ano do Ensino Fundamental I e que não apresentassem nenhum tipo de déficit, dificuldade ou comprometimento cognitivo. Além disso, os estudos teriam de abordar testes de consciência fonológica e de leitura. Assim sendo, seis títulos foram encontrados e somente um artigo foi excluído, por não se enquadrar nos critérios descritos. O Quadro 1 traz os dados do corpus de análise do estudo.

Quadro 1 - Corpus de análise do estudo

\begin{tabular}{|l|l|l|l|}
\hline Título do trabalho & Nomes dos autores & $\begin{array}{l}\text { Título da } \\
\text { Revista }\end{array}$ & Ano \\
\hline $\begin{array}{l}\text { Compreensão de leitura e } \\
\text { consciência fonológica: evidências } \\
\text { de validade de suas medidas }\end{array}$ & $\begin{array}{l}\text { Adriana C. B. Suehiro } \\
\text { Acácia A.A. dos Santos }\end{array}$ & $\begin{array}{l}\text { Estudos de } \\
\text { Psicologia I }\end{array}$ & 2015 \\
\hline $\begin{array}{l}\text { A contribuição da consciência } \\
\text { fonológica, memória de trabalho } \\
\text { e velocidade de nomeação na } \\
\text { aquisição inicial da leitura }\end{array}$ & $\begin{array}{l}\text { Sandra Puliezi } \\
\text { Maria R. Maluf }\end{array}$ & $\begin{array}{l}\text { Boletim } \\
\text { Academia } \\
\text { Paulista de } \\
\text { Psicologia }\end{array}$ & 2012 \\
\hline $\begin{array}{l}\text { Influência da consciência } \\
\text { fonológica na aquisição de } \\
\text { leitura }\end{array}$ & $\begin{array}{l}\text { Laura G. Cavalheiro } \\
\text { Michele S. dos Santos } \\
\text { Poliana C. Martinez }\end{array}$ & $\begin{array}{l}\text { Revista } \\
\text { CEFAG }\end{array}$ & 2010 \\
\hline $\begin{array}{l}\text { O papel da consciência fonológica } \\
\text { na leitura contextual medida para } \\
\text { teste de Cloze }\end{array}$ & $\begin{array}{l}\text { Márcia M. P. E da Mota } \\
\text { Acácia A.A. dos Santos }\end{array}$ & $\begin{array}{l}\text { Estudos de } \\
\text { Psicologia I }\end{array}$ & 2009 \\
\hline $\begin{array}{l}\text { Princípio alfabético e consciência } \\
\text { fonológica: fatores determinantes } \\
\text { no tempo de leitura de crianças } \\
\text { em processo de alfabetização }\end{array}$ & Ana P. R. Scherer & Signo & 2007 \\
\hline
\end{tabular}

Fonte: Elaborado pelas autoras. 


\section{Descrição dos trabalhos selecionados}

A partir da delimitação do corpus feita, os artigos foram analisados detalhadamente. Quanto às características gerais, as publicações são recentes, compreendem os anos de 2007 a 2015, quatro delas provêm de São Paulo e uma do Rio Grande do Sul, sendo que as áreas de produção dos artigos são: três da Psicologia e dois da Fonologia.

Os indivíduos que contribuíram com dados para as pesquisas frequentavam o Ensino Fundamental, tinham de 6 a 12 anos, apresentavam desenvolvimento típico e estavam adquirindo a modalidade escrita da língua materna. A instituição de ensino de onde os participantes procedem é variada, compreende escola pública, privada e, em dois estudos, não foi indicada. Contudo, esse dado não interferiu nos resultados desta pesquisa, visto que a leitura é trabalhada em qualquer instituição. Ademais, o status socioeconômico não foi mencionado, fato que pode influenciar nos dados, pois a estimulação feita anterior ao ingresso da criança na escola pode ter sido díspar, contribuindo para uma maior ou menor competência e consciência de aspectos fonológicos da língua.

No que concerne à forma dos instrumentos de avaliação, de intervenção, observaram-se diversificações quanto à aplicação dos testes. Para avaliar a consciência fonológica, foram utilizados os seguintes testes: Roteiro de Avaliação da Consciência Fonológica (SANTOS, 1996); Prova de Consciência Fonológica por Produção Oral (CAPOVILLA; CAPOVILLA, 1998; CAPOVILLA; CAPOVILLA; SILVEIRA, 1998). O Quadro 2 apresenta as tarefas de consciência fonológica desenvolvidas nos estudos.

Scherer (2007), em seu estudo, não realizou nenhum teste de $\mathrm{CF}$, mas analisou a prática de uma professora que deu ênfase na explicitação do princípio alfabético e trabalhou com atividades de consciência fonológica e a de outra professora que não utilizava esse método, apenas dizia o nome das letras para sua turma. Por trabalhar com consciência fonológica durante o processo de leitura, optou-se em também analisar o trabalho. Com exceção deste trabalho, todos os outros foram analisados estatisticamente.

Para avaliar a compreensão leitora, em dois estudos (SUEHIRO; SANTOS, 2015, MOTA; SANTOS, 2009), foi aplicado o Teste Cloze, que consiste em deixar que a criança leia o texto uma vez e, na segunda vez, complete as lacunas com palavras que façam sentido dentro do contexto. Nos outros estudos foram realizadas outras tarefas para avaliar a leitura, descritas no decorrer desta revisão.

No estudo de Suehiro e Santos (2015), o Roteiro de Avaliação de Consciência Fonológica (RACF) era constituído por três séries, em que cada série continha cinco itens e dois exemplos que visavam a avaliar a dificuldade na identificação do fonema ou som inicial, final e medial. Cada item era composto de uma palavra modelo e outras três palavras como alternativa de resposta. Foi atribuído um ponto para cada acerto e zero para cada erro, sendo 15 a pontuação máxima. A média obtida foi de 11,27 acertos (DP: 2,76), sendo 4 a pontuação mínima e 15 a máxima. As pontuações médias alcançadas no som inicial e som final foram superiores à do som medial.

$\mathrm{Na}$ Prova de Consciência Fonológica por Produção Oral (PCFO), a habilidade avaliada foi a de manipular os sons da fala, expressando oralmente o resultado dessa manipulação. O teste era composto de 10 subtestes, os quais constam no Quadro 2, cada um composto por dois itens de treino e quatro de teste. $\mathrm{O}$ resultado foi

Quadro 2 - Tarefas de consciência fonológica desenvolvidas em cada estudo

\begin{tabular}{|c|c|c|c|c|}
\hline Tarefas & $\begin{array}{c}\text { Suehiro e Santos } \\
\text { (2015) }\end{array}$ & $\begin{array}{l}\text { Puliezi e Maluf } \\
\text { (2012) }\end{array}$ & $\begin{array}{l}\text { Cavalheiro, Santos e } \\
\text { Martinez (2010) }\end{array}$ & $\begin{array}{c}\text { Mota e Santos } \\
\qquad(2009)\end{array}$ \\
\hline Identificação do fonema inicial & $\mathrm{X}$ & $\mathrm{X}$ & & \\
\hline Identificação do fonema final & $\mathrm{x}$ & & & \\
\hline Identificação do fonema no meio da palavra & $\mathrm{X}$ & & & \\
\hline Síntese silábica & $\mathrm{x}$ & & $\mathrm{x}$ & \\
\hline Síntese fonêmica & $x$ & & $x$ & \\
\hline Julgamento de rima & $x$ & $x$ & $x$ & $\mathrm{X}$ \\
\hline Aliteração & $x$ & & $x$ & $\mathrm{x}$ \\
\hline Segmentação silábica & $x$ & $x$ & $x$ & \\
\hline Segmentação fonêmica & $x$ & & $x$ & \\
\hline Manipulação silábica & $x$ & & $x$ & \\
\hline Manipulação fonêmica & $x$ & & $x$ & \\
\hline Transposição silábica & $x$ & & $x$ & \\
\hline Transposição fonêmica & $x$ & & $x$ & \\
\hline
\end{tabular}

Fonte: Elaborado pelas autoras. 
apresentado como escore de acertos, sendo 40 acertos possíveis. A pontuação média foi de 28,04 acertos (desvio padrão: 7,55), 10 a mínima e 40 a máxima. Observou-se que, nas tarefas de síntese silábica, de segmentação silábica e de aliteração, a pontuação média foi superior às demais. Os piores desempenhos ocorreram em: síntese, transposição e segmentação fonêmica. Para verificar se as crianças que obtiveram melhor desempenho na PCFO também o apresentaram com relação à compreensão em leitura, elas foram separadas por ano escolar (SUEHIRO; SANTOS, 2015).

$\mathrm{Na}$ avaliação da leitura, foram apresentados dois textos, de 204 palavras, "A princesa e o fantasma" (Cloze 1) e "Uma vingança infeliz" (Cloze 2), cujas propriedades já tinham sido estabelecidas em estudo anterior no Brasil (SANTOS, 2005) e apresentavam níveis de dificuldade diferentes. Eram consideradas corretas somente as respostas que continham palavras idênticas às omitidas. A pontuação máxima em cada texto era 15 pontos, tendo um total de 30 pontos possíveis no teste de Cloze. As crianças atingiram uma média de 11,10 acertos no Cloze Total (desvio padrão: 7,36) com pontuações de 0 a 24 pontos. A pontuação média e o desvio padrão obtidos no Cloze 1 foram superiores aos do Cloze 2 (M: 6,61; DP: 4,13 e M: 4,50; DP: 3,58, respectivamente) (SUEHIRO; SANTOS, 2015).

A partir do teste não paramétrico Mann-Whitney-U, verificou-se que as crianças com desempenho superior no PFCO também alcançaram pontuações médias superiores no Cloze. Além disso, teve-se a comprovação de que as crianças que tiveram melhor desempenho no PCFO também o apresentaram com relação ao RACF (SUEHIRO; SANTOS, 2015).

No estudo de Puliezi e Maluf (2012), a primeira tarefa de CF consistia na separação silábica de 15 palavras (5 monossílabas, 5 dissílabas, 5 trissílabas e 3 itens de ensaio). A imagem era mostrada no computador, com o acerto era atribuído um ponto e, com o erro, zero, sendo que o máximo era de 15 pontos. A tarefa de rima constituiu em identificar, entre três palavras diferentes, aquela que não rimava com as outras. As imagens foram mostradas no computador, deviam ser repetidas pela criança que, em seguida, designavam aquela que não rimava. $\mathrm{O}$ escore máximo atribuído foi de 10 pontos. E a segunda tarefa era de identificação da palavra que começava com o fonema inicial diferente das outras. O escore máximo atribuído também foi de 10 pontos.

Nesse estudo, a seleção das palavras (30 palavras com grafias frequentes em livros infantis) para a avaliação da habilidade de leitura também já havia sido usada em outro estudo (CARDOSO-MARTINS, BATISTA, 2005). Se a criança lia uma sílaba, recebia meio ponto, se lia a palavra inteira, um ponto, alcançando um escore máximo de 60 pontos. O tempo de leitura foi registrado (PULIEZI; MALUF, 2012).

Além dos testes de CF e de leitura, Puliezi e Maluf (2012) realizaram duas tarefas para avaliar a memória de trabalho (MT), sendo uma delas para avaliar a memória sequencial auditiva, que consistia na repetição de 21 sequências de dígitos, que continham de 2 a 7 dígitos em cada sequência. A criança podia tentar duas vezes. E outra tarefa era a de repetição de pseudopalavras (sequências fonológicas sem significado). A tarefa era composta por 30 pseudopalavras, de estrutura silábica simples, seguindo a estrutura fonológica do português. As palavras foram dispostas em seis listas e cada uma continha cinco pseudopalavras. A resposta era considerada incorreta quando o aluno omitia, substituía ou não produzia os fonemas ou quando não produzia a pseudopalavra.

Para avaliar a velocidade de nomeação (VN), foi utilizada a tarefa de denominação de figuras. A criança tinha de denominar as figuras (que eram palavras dissílabas e de estrutura silábica consoante-vogal) o mais rapidamente possível, na sequência em que apareciam. O tempo de execução foi medido duas vezes e foi calculado o tempo médio. Com base no desempenho apresentado, as crianças foram categorizadas em três grupos: bons leitores - de 58 a 60 pontos; maus leitores - de 0 a 50 pontos e grupo intermediário - de 51 a 57 pontos. Para a análise, foram considerados apenas os grupos extremos. As crianças do grupo dos bons leitores possuíram os melhores tempos de leitura e os melhores escores na tarefa de velocidade de nomeação, nas tarefas de identificação de rima e fonema e nas tarefas que avaliaram a memória de trabalho fonológica, os escores também foram mais altos (PULIEZI; MALUF, 2012). Nas tarefas de CF, os dois grupos (bons e maus leitores) tiveram resultados semelhantes quando segmentaram palavras. Os erros se concentravam nas 5 palavras monossílabas, pois as crianças tentavam "hipersegmentá-las". Com relação à memória de trabalho fonológica, a pontuação média na tarefa de repetição de dígitos no grupo dos bons leitores foi de 9,73 e no grupo dos maus leitores de 8,5. Na tarefa de pseudopalavras, foi 14,01 a dos bons leitores e 12,01 a dos maus leitores. Por esse motivo, pode-se concluir que existe uma relação entre memória fonológica e desempenho em leitura. O grupo de maus leitores teve escores piores em: velocidade de nomeação, consciência fonológica e memória de trabalho (PULIEZI; MALUF, 2012).

A partir do Teste-T de Student foi possível perceber que o grupo dos bons leitores apresentou diferença significativa no que diz respeito à velocidade de nomeação e à CF. Já na memória de trabalho, o mesmo grupo apresentou bons resultados, contudo, a diferença não foi estatisticamente significativa. Além disso, o 
teste de correlação de Pearson permitiu mostrar que o tempo gasto na tarefa de nomeação diminuía na medida em que aumentava a habilidade de leitura. A correlação entre leitura e MT foi menos forte, porém significativa (PULIEZI; MALUF, 2012).

Cavalheiro, Santos e Martinez (2010) também aplicaram a Prova de Consciência Fonológica (PCF), organizada por Capovilla e Capovilla (1998), que é composta por dez subtestes que estão marcados no Quadro 2. Os resultados foram apresentados por frequência de acertos, podendo atingir um máximo de 40 pontos, de acordo com o nível de escolaridade.

As autoras basearam-se em outros estudos (CAVALHEIRO; SANTOS; MARTINEZ, 2010) para avaliar a velocidade da leitura. Foram utilizados os textos "As travessuras de Afonsinho" e "Os três irmãos" com similaridade no número total de palavras e uso de palavras regulares e irregulares. Individualmente, a criança fazia a leitura oral do primeiro texto e, após cinco minutos do início, a pesquisadora pedia para que a última palavra lida fosse indicada para fazer a marcação e análise de quantas palavras a criança havia lido por minuto. Foram feitas cinco perguntas de compreensão sobre o texto. Em seguida, a criança realizava a leitura silenciosa do segundo texto e o mesmo procedimento era feito. Uma resposta certa já implicava presença de compreensão parcial, e a ocorrência de respostas corretas para todas as perguntas significava compreensão total. Esse critério valeu apenas para as crianças em nível de leitura alfabético (CAVALHEIRO; SANTOS; MARTINEZ, 2010).

O desempenho apresentado pelos participantes na PCF foi comparado com valores encontrados em outro estudo e analisado estatisticamente por meio do teste T de Student. O teste de Wilcoxon comparou e verificou a diferença entre as pontuações das habilidades silábicas e fonêmicas. O teste Kruskal-Wallis foi aplicado para verificar a diferença nas pontuações da PCF. Também foi usado o coeficiente a correlação de Spearman para verificar a correlação existente entre a velocidade de leitura oral com a pontuação total de PCF, das habilidades silábicas e fonêmicas (CAVALHEIRO; SANTOS; MARTINEZ, 2010).

A maior parte dos participantes apresentou-se no nível de leitura logográfico (45\%) e alfabético sem compreensão (43,3\%), enquanto o nível alfabético com compreensão correspondeu a $11,6 \%$ dos pesquisados e não houve participantes no nível de leitura ortográfico. A média de velocidade na leitura oral foi de 10,09 palavras por minuto, enquanto a média na leitura silenciosa se apresentou superior, 47,38 palavras por minuto (CAVALHEIRO; SANTOS; MARTINEZ, 2010).

Pôde-se observar que a consciência fonológica estava abaixo do esperado para a escolaridade dos participantes avaliados, sendo que os aspectos relacionados à consciência fonêmica apresentaram menores escores em relação aos aspectos suprafonêmicos, revelando que há uma hierarquia de aquisição. Observou-se que a velocidade de leitura oral se apresentou baixa para todos os escolares, o que corrobora a afirmação de que crianças de séries iniciais tendem a ler de forma mais lenta, uma vez que o processamento se dá via rota fonológica (CAVALHEIRO; SANTOS; MARTINEZ, 2010).

As crianças com o nível de leitura logográfico foram as que apresentaram piores desempenhos na Prova de Consciência Fonológica com algumas exceções; as que apresentaram o nível de leitura alfabético sem compreensão oscilaram na pontuação da PCF, e as que apresentaram o alfabético com compreensão como nível de leitura obtiveram melhor pontuação. Esses resultados afirmam que a presença da consciência fonológica permite melhor desenvolvimento e desempenho em leitura. Os sujeitos avaliados encontravam-se em processo de aquisição de leitura e possuíam poucas palavras no seu léxico visual, usavam preferencialmente a rota fonológica, o que podia estar determinando lentidão na velocidade de leitura oral. As crianças que apresentaram maior habilidade na manipulação dos sons da fala conseguiram desenvolver velocidade e nível de leitura de maneira mais eficiente (CAVALHEIRO; SANTOS; MARTINEZ, 2010).

No estudo de Mota e Santos (2009), a tarefa de consciência fonológica foi a categorização de rima e aliteração. A criança tinha de decidir qual palavra não tinha o mesmo som que outras em duas listas, sendo a primeira rima e a segunda aliteração. $\mathrm{O}$ escore total era de 12 pontos. Nesse estudo também foi realizado o teste Cloze com dois textos, cujas propriedades já tinham sido estabelecidas em estudo anterior no Brasil (SANTOS, 2005). O escore era de 15 pontos em cada texto. Foram utilizados os subtestes de Vocábulos e Dígitos da Escala de Inteligência Wechsler para crianças - WISC III, para controlar a influência do desenvolvimento cognitivo na aquisição da leitura e da escrita. Para verificar se havia uma associação entre a leitura contextual e a consciência fonológica, memória e vocabulário, foi realizada a correlação de Spearman. Para as tarefas de CF e as duas versões do teste de Cloze, um ponto foi dado para cada resposta correta. (MOTA; SANTOS, 2009)

Os resultados mostraram que escores dos testes de Cloze correlacionaram-se de forma positiva e significativa com as duas medidas de consciência fonológica e apresentaram correlações positivas e significativas com a tarefa de memória de dígitos e com a idade. A medida de vocabulário não se correlacionou de forma positiva e significativa com os escores do Cloze (MOTA; SANTOS, 2009).

Por fim, no estudo de Scherer (2007), a metodologia utilizada foi diferente da dos outros estudos. Um grupo de 
5 alunos (Grupo A) pertencentes a uma turma de $1^{a}$ série recebeu da professora ênfase à explicação do princípio alfabético e outros 5 alunos (Grupo B), de igual série, tiveram com a professora a alfabetização tradicional, que apenas informava o nome das letras. A autora teve como instrumento para a coleta de dados uma lista de 25 pseudopalavras e de 8 frases constituídas por ordens, que a criança deveria cumprir após a leitura, evidenciando a compreensão.

Foi verificado que o Grupo A apresentou tempos de leitura menores que os do Grupo B na leitura de não palavras. A média ficou 2.53 segundos e 3.65 segundos, respectivamente. Em ambos os grupos, o aumento dos tempos de leitura ocorreu conforme o aumento do número de sílabas. Também no tempo de leitura e compreensão de frases, o Grupo A teve tempos menores, sendo 4.98 segundos e o grupo B 11.51 segundos. Com esses resultados, constata-se que a explicitação do princípio alfabético, aliada a atividades de consciência fonológica, influenciou positivamente para que os alunos apresentassem um melhor desempenho em leitura (SCHERER, 2007).

\section{Análise dos trabalhos selecionados}

Esta revisão permitiu constatar, a partir dos resultados de todos os estudos analisados, que a consciência fonológica desempenha um papel de extrema importância na aprendizagem da leitura e na compreensão leitora em sistemas alfabéticos.

Com base nos dados apresentados por Suehiro e Santos (2015), que dizem respeito à performance de alunos em habilidades de CF em nível silábico e fonêmico, pode-se perceber que os participantes tiveram maior dificuldade na manipulação do som intermediário das palavras (dado retirado do RACF) e na síntese, transposição e segmentação fonêmica (dado retirado do PCFO). Como foi visto anteriormente, conforme os níveis de consciência fonológica, a unidade linguística de análise fonêmica é a última a ser atingida. Contudo, pela idade dos participantes, todos os níveis já deveriam ter sido alcançados. Por isso, os achados do estudo indicaram que as crianças avaliadas apresentaram dificuldades na compreensão em leitura e na consciência fonológica.

Outra contribuição do estudo de Suehiro e Santos (2015) foi que, a partir da análise da seriedade dos instrumentos de avaliação de CF e de leitura, constatou-se que eles podem contribuir para a definição de recursos para a prevenção e para a intervenção em ambos os construtos analisados. Tendo em vista as limitações do estudo, as autoras sugerem pesquisas futuras, que utilizem uma amostra maior e que incluam alunos de escolas, tanto particulares, quanto públicas, excluindo crianças com defasagem de série, o que não foi feito no estudo, visando à ampliação dos conhecimentos na área e aprimoramento dos instrumentos e procedimentos técnicos empregados na avaliação psicoeducacional.

Os resultados da pesquisa de Puliezi e Maluf (2012) constataram que a habilidade em leitura se correlacionou com a consciência fonológica nas duas análises estatísticas efetuadas, fato que foi ao encontro de vários estudos já realizados na área.

Esses resultados evidenciaram a importância fonológica no início da aquisição da leitura, reforçando resultados de vários estudos brasileiros que também encontraram essas relações, como Cardoso-Martins (1995); Maluf e Barrera (1997); Barrera e Maluf (2003) e Capovilla A.G.S, Gütschow e Capovilla F. C. (2004). Mota e Santos (2009) acrescentam os trabalhos de Capovilla e Capovilla (2000); Guimarães (2003), Petsun (2005), Santos (1996) e Zucoloto e Sisto (2002) (PULIEZI; MALUF, 2012, p. 224).

Os estudos brasileiros acima citados não entraram na análise desta revisão sistemática por não apresentarem as palavras-chave e os critérios de inclusão no título ou no resumo. Analisando somente a $\mathrm{CF}$, ficou evidente, para as autoras, que as habilidades de identificação de rima e fonema mostraram-se como sendo importantes para diferenciar bons e maus leitores, pois os bons leitores tiveram ótimo desempenho nessas tarefas. $\mathrm{Na}$ tarefa de segmentação silábica, as crianças tiveram melhor desempenho, contudo, o erro era maior quando as palavras eram monossílabas. Isso ocorreu porque a tarefa exige um determinado nível de consciência fonêmica para ser realizada com êxito.

As diferenças observadas nas tarefas de CF e na de velocidade de nomeação nos grupos de bons e maus leitores são significativas. As variações que ocorrem na leitura estão relacionadas às variações que ocorrem nessas duas habilidades, portanto, bons leitores nomeiam com mais rapidez e têm as habilidades de CF mais desenvolvidas do que os maus leitores. Em vista disso, é possível afirmar que os processamentos cognitivos, como CF, memória de trabalho e velocidade de nomeação contribuíram significativamente para a aprendizagem inicial da leitura. A limitação do estudo é que a amostra é pequena, e as autoras sugerem em um próximo estudo ampliar a faixa etária dos informantes.

Cavalheiro, Santo e Martinez (2010) indicaram que existe correlação positiva fraca significativa entre $\mathrm{CF}$, principalmente as habilidades em consciência silábica e fonêmica, e o desenvolvimento da velocidade e do nível de leitura. Com relação à consciência fonológica, pôde-se observar que os participantes estão abaixo do esperado para a sua escolaridade. Contudo, aqueles que 
já estavam em nível mais avançado de leitura também obtiveram melhor pontuação na PCF, evidenciando que a presença de consciência fonológica permite melhor desenvolvimento e desempenho em leitura. O tempo de leitura oral também foi maior ao esperado, pois muitos participantes encontravam-se no nível alfabético de leitura e utilizavam a rota fonológica para ler. Quando testada a leitura silenciosa apresentaram tempos menores, isso pode ter acontecido em função de ocorrer pouco monitoramento na leitura ou, até mesmo, a realização da leitura de palavras de maior complexidade por adivinhação.

Já Mota e Santos (2009) constataram que rima e aliteração apresentaram correlações positivas e significativas com a leitura contextual, assim como o teste de memória de dígitos apresentou escores positivos. Em razão disso, os resultados sugerem que as práticas de ensino de leitura e da escrita devem envolver o ensino das regras de correspondência entre letra e som.

E, para concluir, a observação dos dados de Scherer (2007) mostra que o Grupo A obteve melhores resultados nas tarefas. Dessa forma, fica evidente que, a partir do método adotado pela professora, no caso o princípio alfabético, aliado à consciência fonológica, é que os alunos apresentaram melhores desempenhos em leitura, o que mostra a importância da utilização dos recursos didáticos e metodológicos no processo de alfabetização, mais especificamente, no de leitura em língua materna.

\section{Considerações finais}

Compreender que podemos desde cedo favorecer o desenvolvimento de habilidades em consciência fonológica quando oferecemos oportunidades de linguagem falada e escrita (SCHERER, 2012a,b) é fundamental para que as instiguemos antes mesmo de adentrarem a escola. Todos os estudos desta revisão sistemática contribuíram para entender que a consciência fonológica desempenha importante função no processo de leitura e compreensão leitora de crianças em processo de aprendizagem da língua escrita. Quando há a $\mathrm{CF}$, o desempenho do indivíduo na leitura e na compreensão leitora melhora, pois os bons leitores obtiveram melhores resultados em tarefas de CF. Além disso, a maior pontuação na prova de CF confere com maior velocidade de leitura. E ainda, explicitação do princípio alfabético e atividades de CF contribuíram para que os participantes obtivessem tempos menores tanto na leitura de pseudopalavras quanto na leitura e compreensão de frases. Essas considerações apontam para a reflexão que ajuda a responder à pergunta norteadora desta revisão.

Cada vez mais, têm-se enfatizado a importância da continuidade dos estudos sobre as implicações do desenvolvimento da consciência fonológica para a aprendizagem da leitura, especialmente no que se refere à compreensão. Também foi possível perceber nos artigos a preocupação na utilização de testes anteriormente aplicados, para que os dados fossem fidedignos. Porém, há ainda a necessidade de se criar instrumentos que possibilitem interpretações mais seguras.

Esta revisão possui limitações, uma vez que é pequeno o número de estudos incluídos. À proporção que novos estudos forem publicados, estes poderão ser agregados e a análise poderá ser atualizada. Por fim, cabe ressaltar a necessidade de se realizarem estudos a respeito de consciência fonológica e leitura e/ou compreensão leitora também na área da Linguística Aplicada, pois compreender esse processo é fundamental para profissionais que trabalham e estudam as línguas naturais e que podem contribuir para que as práticas educativas sejam mais eficazes.

\section{Referências}

ALVES, Ubiratã Kickhöfel. O que é consciência fonológica. In: LAMPRECHT, Regina Ritter; BLANCO-DUTRA, Ana Paula; SCHERER, Ana Paula Rigatti; BARRETO, Fernanda Menna; BRISOLARA, Luciene Bassols; SANTOS, Rosangela Marostega; ALVES, Ubiratã Kickhöfel (org). Consciência dos sons da língua: subsídios teóricos e práticos para alfabetizadores, fonoaudiólogos e professores de língua inglesa. Porto Alegre: EDIPUCRS, 2012. p. $29-40$.

BARRERA, Sylvia D. Papel facilitador das habilidades metalinguísticas na aprendizagem da linguagem escrita. In: MALUF, Maria R. (org.). Metalinguagem e aquisição da escrita: contribuições da pesquisa para a prática da alfabetização. São Paulo: Casa do Psicólogo, 2003. p. 65-90.

BARRERA, Sylvia D.; MALUF, Maria Regina. Consciência metalinguística e alfabetização: um estudo com crianças da primeira série do ensino fundamental. Psicologia, Reflexão e Crítica, Porto Alegre, v. 16, n. 3, p. 491-502, 2003. https://doi. org/10.1590/S0102-79722003000300008

BLANCO-DUTRA, Ana P.; SCHERER, Ana P. R.; BRISOLARA, Luciene B. Consciência fonológica e aquisição de língua materna. In: LAMPRECHT, Regina Ritter; BLANCO-DUTRA, Ana Paula; SCHERER, Ana Paula Rigatti; BARRETO, Fernanda Menna; BRISOLARA, Luciene Bassols; SANTOS, Rosangela Marostega; ALVES, Ubiratã Kickhöfel (org). Consciência dos sons da língua: subsídios teóricos e práticos para alfabetizadores, fonoaudiólogos e professores de língua inglesa. Porto Alegre: EDIPUCRS, 2012. p. $75-91$

BRADLEY, L.; BRYANT, P. E. Categorizing sounds and learning to read: A causal connection. Nature, [s. l.], v. 301, p. 419-421, 1983. https://doi.org/10.1038/301419a0 
CAPELLINI, Simone Aparecida; CAVALHEIRO, Laura Giotto. Avaliação do nível e da velocidade de leitura em escolares com e sem dificuldade na leitura. Temas sobre Desenvolvimento, São Paulo, v. 9, n. 51, p. 5-12, 2000.

CAPOVILLA, Alessandra Gotuzzo Seabra; CAPOVILLA, Fernando César. Prova de consciência fonológica: desenvolvimento de dez habilidades da pré-escola à segunda série. Temas sobre Desenvolvimento, São Paulo, v. 7, n. 37, p. 14-20, 1998.

CAPOVILLA, Alessandra Gotuzzo Seabra; CAPOVILLA, Fernando César; SILVEIRA, F. B. O desenvolvimento da consciência fonológica, correlações com leitura e escrita e tabelas de estandardização. Ciência Cognitiva: Teoria, Pesquisa e Aplicação, [s. l.], v. 2, n. 3, p. 113-160, 1998.

CAPOVILLA, Alessandra Gotuzzo Seabra; GUTSCHOW, Cláudia Regina Danelon; CAPOVILLA, Fernando César. Habilidades cognitivas que predizem competência de leitura e escrita. Psicologia Teoria e Prática, São Paulo, v. 6, n. 2, p. 13-26, 2004.

CARDOSO-MARTINS, Cláudia. Sensitivity to rhymes, syllables, and phonemes in literacy acquisition in Portuguese. Reading Research Quarterly, Newark, Del., US, n. 30, p. 808-828, 1995. https://doi.org/10.2307/748199

CARDOSO-MARTINS, Cláudia; BATISTA, Ana Cláudia Eutrópio. O conhecimento do nome das letras e o desenvolvimento da escrita: evidência de crianças falantes do português. Psicologia: Reflexão \& Crítica, Porto Alegre, v. 18 , n. 3, p. 330-336, 2005. https://doi.org/10.1590/S010279722005000300006

CAVALHEIRO, Laura Giotto; SANTOS, Michele dos Santos.; MARTINEZ, Poliana Carvalho. Influência da consciência fonológica na aquisição de leitura. Revista CEFAC, São Paulo, v. 12, n. 6, p. 1009-1016, nov.-dez. 2010. https://doi.org/10.1590/S1516-18462010005000063

CIELO, Carla Aparecida; POERSCH, José Marcelino.Relação entre a sensibilidade fonológica e o aprendizado inicial da leitura. Letras de Hoje, Porto Alegre, n. 2, p. 99-105, jun. 1998.

COLTHEART, Max. Modelando a leitura: a abordagem da dupla rota. In: SNOWLING, Margaret J.; HULME, Charles (org.). A ciência da leitura. Porto Alegre: Penso, 2013. p. 24-41.

DEHAENE, Stanislas. Os neurônios da leitura: como a ciência explica nossa capacidade de ler. Tradução Leonor Scliar-Cabral. Porto Alegre: Penso, 2012.

GOMBERT, Jean Emile. Atividades metalinguísticas e aprendizagem da leitura. In: MALUF, Maria R. (org). Metalinguagem e aquisição da escrita: contribuições da pesquisa para a prática da alfabetização. São Paulo: Casa do Psicólogo, 2003. p. 19-63.

GOSWAMI, U.; BRYANT, P. Phonological Skills and Learning to Read. London: Lawrence Erlbaun Associates, 1990. $166 \mathrm{p}$.
KARMILOFF-SMITH, Annette. From meta-processes to conscious access: evidence from children's metalinguistic and repair data. Cognition, Amsterdam, NL, v. 23, p. 95-147, 1986. https://doi.org/10.1016/0010-0277(86)90040-5

KARMILOFF-SMITH, Annette. Beyond Modularity: a developmental perspective on cognitive science. Cambridge (MA): MIT, 1992, 234 p. https://doi.org/10.1017/S0140525 $\mathrm{X} 00036621$

KARMILOFF-SMITH, Annette. Précis of Beyond modularity: a developmental perspective on cognitive science. Behavioral and brain sciences, Cambridge, v.17, p. 693-745, 1994.

LORANDI, A. From sensitivity to awareness: the morphological knowledge of brazilian children between 2 and 11 years old and the representational redescription model. 2010. 200f. Tese (Doutorado) - Pontifícia Universidade Católica do Rio Grande do Sul, Porto Alegre, RS, 2011. Disponível em: http://repositorio.pucrs.br/dspace/ handle/10923/4204. Acesso em: 07 jun. 2018.

LORANDI, Aline; MARQUES, Débora Matos. Subsídios teóricos e práticos para a elaboração de testes de consciência linguística. Revista Escrita, Rio de Janeiro, v. 21, p. 1-20, 2016. Disponível em: https://www.maxwell.vrac.puc-rio.br/ 25993/25993.PDFXXvmi=5wjp5D9Np7J2wjkPMbUjvao 7bP68uDfAaA1 fea4EhNHP82GUdBfKLESWu060DIBN WC4cN8R6VzW5BD0PegB1VuZqu5q9r3WoG1Bu9sB63zb Fdcvss8tpDtQ9ziillgq2i3wsw9zAJLgWZMpsUUSzoJJx 220ojrrCu0539FDSrTQqHhTCcNbCwUBAxB0i4rVzr 2CCHguabmBSEvv RjItRE5rCHrVMURImTZZCguMs RomwUSofBT7f0zSI2OuxHQkB. Acesso em: 09 nov. 2017.

MOTA, Márcia Maria Peruzzi Elia da; SANTOS, Acácia Aparecida Angeli dos. O papel da Consciência Fonológica na leitura contextual medida pelo teste de Cloze. Estudos de Psicologia, Natal, v. 14, n. 3, p. 207-212, set.-dez. 2009. https://doi.org/10.1590/S1413-294X2009000300004

PLAUT, David C. Abordagens conexionistas à leitura. In: SNOWLING, Margaret J.; HULME, Charles (org.). A ciência da leitura. Porto Alegre: Penso, 2015.

PULIEZI, Sandra; MALUF, Maria R. A contribuição da consciência fonológica, memória de trabalho e velocidade de nomeação na aquisição inicial da leitura. Boletim Academia Paulista de Psicologia, São Paulo, v. 32, n. 82, p. 213-227, 2012.

SANTOS, Acácia Aparecida Angeli dos. A influência da consciência fonológica na aquisição da leitura e da escrita. In: SISTO, Fermino Fernandes; OLIVEIRA, Gislene de Campos; FINI, Lucila Diehel Tolaine; SOUZA, Maria Thereza Costa Coelho de; BRENELLI, Rosely Palermo (ed.). Atuação psicopedagógica e aprendizagem escolar. Petrópolis: Vozes,1996. p. 213-247.

SANTOS, Acácia Aparecida Angeli dos. O Teste de Cloze como instrumento de diagnóstico e de desenvolvimento da compreensão em leitura (Relatório Técnico de Bolsista Produtividade enviado ao CNPq). Universidade São Francisco, Itatiba, 2005. 
SCHERER, Ana Paula Rigatti. Princípio alfabético e consciência fonológica: fatores determinantes no tempo de leitura de crianças em processo de alfabetização. Signo, Santa Cruz do Sul, v. 32, n. 53, p. 82-99, 2007.

SCHERER, Ana Paula Rigatti. Conversa inicial. In: LAMPRECHT, Regina Ritter; BLANCO-DUTRA, Ana Paula; SCHERER, Ana Paula Rigatti; BARRETO, Fernanda Menna; BRISOLARA, Luciene Bassols; SANTOS, Rosangela Marostega; ALVES, Ubiratã Kickhöfel (org.). Consciência dos sons da língua: subsídios teóricos e práticos para alfabetizadores, fonoaudiólogos e professores de língua inglesa. Porto Alegre: EDIPUCRS, 2012a. p. 23-26.

SCHERER, Ana Paula Rigatti. Consciência fonológica na alfabetização infantil. In: LAMPRECHT, Regina Ritter; BLANCO-DUTRA, Ana Paula; SCHERER, Ana Paula Rigatti; BARRETO, Fernanda Menna; BRISOLARA, Luciene Bassols; SANTOS, Rosangela Marostega; ALVES, Ubiratã Kickhöfel (org.). Consciência dos sons da língua: subsídios teóricos e práticos para alfabetizadores, fonoaudiólogos e professores de língua inglesa. Porto Alegre: EDIPUCRS, 2012b. p. 109-119.

SUEHIRO, Adriana Cristina Boulhoça; SANTOS, Acácia Aparecida Angeli dos. Compreensão de leitura e consciência fonológica: evidências de validade de suas medidas. Estudos de Psicologia, Campinas, v. 32, p. 201-211, abr.-jun. 2015. https://doi.org/10.1590/0103-166X2015000200005

WOLF, Clarice Lehnen. Descobrindo as rimas em poemas: estudo sobre os efeitos das rimas na consciência fonológica e suas relações com os demais níveis de consciência linguística durante o processo de alfabetização. 2015. 285f. Tese (Doutorado em Letras) - Pontifícia Universidade Católica do Rio Grande do Sul: Porto Alegre, 2015.

Recebido em: 15/11/2018

Aprovado em: 12/6/2019

Publicado em: 5/11/2019.

\section{Autores:}

JORDANA TAÍS KONRAD

Mestre em Linguística Aplicada pela Universidade do Vale do Rio dos Sinos (Unisinos), São Leopoldo, RS, Brasil. Especialista em Neurociência e Educação pelo Instituto Superior Ivoti, Ivoti, RS, Brasil. Professora no Instituto Superior Ivoti, Ivoti, RS, Brasil.

Orcid: https://orcid.org/0000-0003-1014-6188

E-mail: jordana.konrad.jtk@gmail.com

\section{ALINE LORANDI}

Doutora em Letras/Linguística pela Pontifícia Universidade Católica do Rio Grande do Sul (PUCRS), Porto Alegre, RS, Brasil. Pós-doutora em Neurociência Cognitiva pelo Birkbeck College, University of London, Londres, Inglaterra. Professora no Programa de Pós-Graduação em Linguística Aplicada da Universidade do Vale do Rio dos Sinos (Unisinos), São Leopoldo, RS, Brasil.

Orcid: http://orcid.org/0000-0002-3886-4950

E-mail: alinelorandi@gmail.com

Endereço: Universidade do Vale do Rio dos Sinos

Av. Unisinos, 950 - Cristo Rei

93022-750, São Leopoldo, RS, Brasil 